\title{
Upregulation of miR-3658 in bladder cancer and tumor progression
}

\author{
Y.J. Chen ${ }^{1,2 *}$, H.F. Wang ${ }^{1 *}$, M. Liang ${ }^{3 *}$, R.C. Zou ${ }^{1}$, Z.R. Tang ${ }^{1}$ and \\ J.S. Wang ${ }^{1}$ \\ ${ }^{1}$ Department of Urology, \\ The Second Affiliated Hospital of Kunming Medical University, \\ Yunnan Institute of Urology, Kunming, Yunnan Province, China \\ ${ }^{2}$ The Second Department of Nephrology, \\ The Fourth Affiliated Hospital of Dali University, \\ Chuxiong People's Hospital, Chuxiong, Yunnan Province, China \\ ${ }^{3}$ Department of Urology, Gejiu People's Hospital, Gejiu, \\ Yunnan Province, China \\ *These authors contributed equally to this study. \\ Corresponding author: J.S. Wang \\ E-mail: jiansongwangkm@126.com
}

Genet. Mol. Res. 15 (4): gmr15049048

Received August 1, 2016

Accepted September 5, 2016

Published November 3, 2016

DOI http://dx.doi.org/10.4238/gmr15049048

Copyright (C) 2016 The Authors. This is an open-access article distributed under the terms of the Creative Commons Attribution ShareAlike (CC BY-SA) 4.0 License.

ABSTRACT. Despite increasing advances in surgical techniques and adjuvant chemotherapies, bladder cancer remains the ninth leading cause of male malignancy-associated deaths worldwide. Several microRNAs (miRNAs) have been identified to be closely associated with the progression and prognosis of, and response to treatments in various human cancers. However, few studies have investigated the role of miR-3658 in bladder cancer. In this study, we examined the expression of miR-3658 in 96 pairs of bladder cancer tissues and adjacent non-tumor tissues via quantitative reverse-transcription polymerase 
chain reaction. Results showed that expression of miR-3658 was upregulated in the bladder cancer tissues as compared with that in the corresponding control tissues $(4.15 \pm 2.78$ vs $2.17 \pm 1.14$; $\mathrm{P}<0.0001)$. Furthermore, higher miR-3658 expression was significantly associated with lymph node invasion, distant metastasis, histological grade, TNM stage, and tumor recurrence in bladder cancer (all $\mathrm{P}<0.0001$ ). miR3658 expression was not associated with other clinicopathological variables such as age, gender, tumor size, and number (all $\mathrm{P}>0.05$ ). Our study revealed that miR-3658 overexpression is involved in tumor progression of bladder cancer, indicating that the miRNA possesses prognostic values.

Key words: miR-3658; Bladder cancer; Clinical pathological parameters; Tumor progression

\section{INTRODUCTION}

Bladder cancer is a major unsolved public health problem, and is the ninth leading cause of male malignancy-related deaths. It is estimated that worldwide there are 429,800 new cases of and 165,100 deaths per year due to bladder cancer (Torre et al., 2015). Despite increasing advances in surgical techniques and adjuvant chemotherapies, prognosis of bladder cancer is extremely poor owing to high recurrence rate and metastatic potential (Herr, 1999; Sylvester et al., 2006; Cambier et al., 2016). Studies have shown that recurrence rate of bladder cancer is approximately $15-50 \%$, and may even reach nearly $70 \%$ (Hisataki et al., 2000; Mehta et al., 2015). Therefore, it is vital to define novel prognostic biomarkers and new molecular drug targets in this disease.

MicroRNAs (miRNAs) are endogenous, small, noncoding RNAs that are approximately 22 nucleotides in length. Studies have shown that miRNAs are closely associated with progression and prognosis of, and response to treatments in human cancer via transcriptional and posttranscriptional gene regulation (Calin and Croce, 2006; Meister, 2007). A single miRNA may target hundreds of mRNAs, and is therefore involved in multiple physiological and pathological processes, including cell proliferation, differentiation, apoptosis, and tumorigenesis (Calin et al., 2004). For example, miR-19 was identified to play crucial roles in rheumatoid arthritis and bladder cancer by targeting Toll-like receptor 2 and phosphatase and tensin homolog, respectively (Philippe et al., 2012; Feng et al., 2014). Accumulating evidence revealed that several miRNAs play important roles in the tumorigenesis and progression of various cancers by acting as tumor suppressors or oncogenes (Hede, 2005; Yu et al., 2010; Catto et al., 2011; Fan et al., 2013; Han et al., 2013; Drayton et al., 2014; Feng et al., 2014; Wang et al., 2013, 2015). By microarray analysis, we recently found several miRNAs to be associated with bladder cancer. Of these miRNAs, miR-3658 was significantly up-regulated with a 166-fold increase in expression as compared to that in the controls (Liu et al., 2016). Similarly, miR-3658 was reported to be over-expressed in multiple myeloma (Hao et al., 2015). However, few studies have examined miR-3658 in detail. The aberrant expression of miR-3658 and its correlations with clinical and pathological characteristics of bladder cancer are still poorly understood.

Therefore, the aim of the present study was to further explore the relationships between miR-3658 expression and bladder cancer.

Genetics and Molecular Research 15 (4): gmr15049048 


\section{MATERIAL AND METHODS}

\section{Patients and samples}

The study consisted of 96 patients with urothelial carcinoma; disease was confirmed by surgical pathology. Between 2014 and 2015, patients who had undergone radical cystectomy at the Urology Department of the Second Hospital affiliated to Kunming Medical University were recruited into the study. Written informed consent was obtained from all subjects prior to enrollment, and the study protocol was approved by the local medical Ethics Committee. No patient had received preoperative chemotherapy or radiotherapy. For quantitative reverse-transcription polymerase chain reaction (qRTPCR) we collected fresh bladder cancer tissues following radical cystectomy, and the corresponding adjacent non-tumor tissues from the macroscopic tumor margin were used as controls. All samples were placed immediately in liquid nitrogen and stored at $-80^{\circ} \mathrm{C}$ until RNA extraction.

\section{Clinicopathological parameters of the patients}

All cases were classified according to the tumor-node-metastasis (TNM) system set by the Union International Cancer Control (UICC) in 2002. The urothelial carcinoma pathologyclassification system (2004) set by the World Health Organization was used to classify tumor grade. The clinicopathological parameters for the 96 patients included age, gender, tumor size, tumor number, tumor occurrence (primary or recurrent), lymph node invasion, distant metastasis, histological grade, and TNM stage.

\section{RNA extraction and qRT-PCR}

Total RNA was extracted from frozen tissues, using TRIzol reagent (Invitrogen, Carlsbad, CA, USA) following manufacturer protocol. The 260/280 OD was measured using a NanoDrop spectrophotometer (NanoDrop Technologies, Houston, TX, USA) to assess the concentration and purity of RNA extracted from the samples. Small nucleolar RNA (snRNA) U6 was used as an internal standard for normalization. To determine miR-3658 and snRNA U6 expression, qRT-PCR was performed using the SYBR PrimeScript miRNA RT-PCR kit (Takara Biotechnology Co. Ltd., Dalian, China); $2 \mu \mathrm{L}$ RNA was added to the RT reaction system, and $2 \mu \mathrm{L}$ cDNA served as the template for PCR amplification. Reactions were carried out in triplicates on an Applied Biosystems 7500 Real-Time PCR systems (Applied Biosystems, Carlsbad, CA, USA). All real-time PCR primers were synthesized by Sangon (Sangon Biotech, Shanghai, China). The primer sequences were as follows: miR-3658 forward: 5'-GTGGGGGTTTAAGAAAACACCAT-3' miR-3658 and reverse: 5'-GTGCAGGGTCCGAGGT-3'; U6 forward: 5'-GCTTCGGCAGCACATATACTAAAAT-3' and U6 reverse: 5'-GTGCAGGGTCCGAGGT-3'. The qRT-PCR cycling parameters were as follows: pre-denaturation at $95^{\circ} \mathrm{C}$ for $30 \mathrm{~s} ; 40$ cycles of denaturation at $95^{\circ} \mathrm{C}$ for $5 \mathrm{~s}$, annealing and extension at $60^{\circ} \mathrm{C}$ for $20 \mathrm{~s}$. Amplification specificity was confirmed by analyzing the melting curve. The cycle threshold $(\mathrm{Ct})$ value was calculated, and the $2^{-\Delta \Delta \mathrm{Ct}}$ method $[\Delta \mathrm{Ct}=\mathrm{Ct}$ (miR3658) - Ct (U6-snRNA)] was followed to quantify the relative expression of miR-3658 (Livak and Schmittgen, 2001).

Genetics and Molecular Research 15 (4): gmr15049048 


\section{Statistical analysis}

Data are reported as means $\pm \mathrm{SD}$. Comparisons of miR-3658 expression in bladder cancer and adjacent non-tumor tissues were performed by the Student $t$-test. Correlations between miR-3658 expression and the clinicopathological parameters were assessed by the two-sample Student $t$-test. Statistical analyses were performed using the SPSS 19.0 software (version 19.0, IBM, Armonk, NY, USA) for Windows, and $\mathrm{P}<0.05$ was considered statistically significant.

\section{RESULTS}

\section{MiR-3658 expression in bladder cancer tissues}

The OD 260/280 ratios of all RNA samples ranged between 1.8 and 2.2, which confirmed that the purity and quality of RNA was adequate for subsequent experiments. We examined miR-3658 expression in 96 pairs of bladder cancer and adjacent non-tumor tissues by qRT-PCR. Results showed that expression levels of miR-3658 were significantly increased in the bladder cancer tissues as compared with that in the corresponding adjacent non-tumor tissues $(4.15 \pm 2.78$ vs $2.17 \pm 1.14)$, with a median 1.91-fold increase $(t=6.46, \mathrm{P}<0.0001)$ (Figure 1).

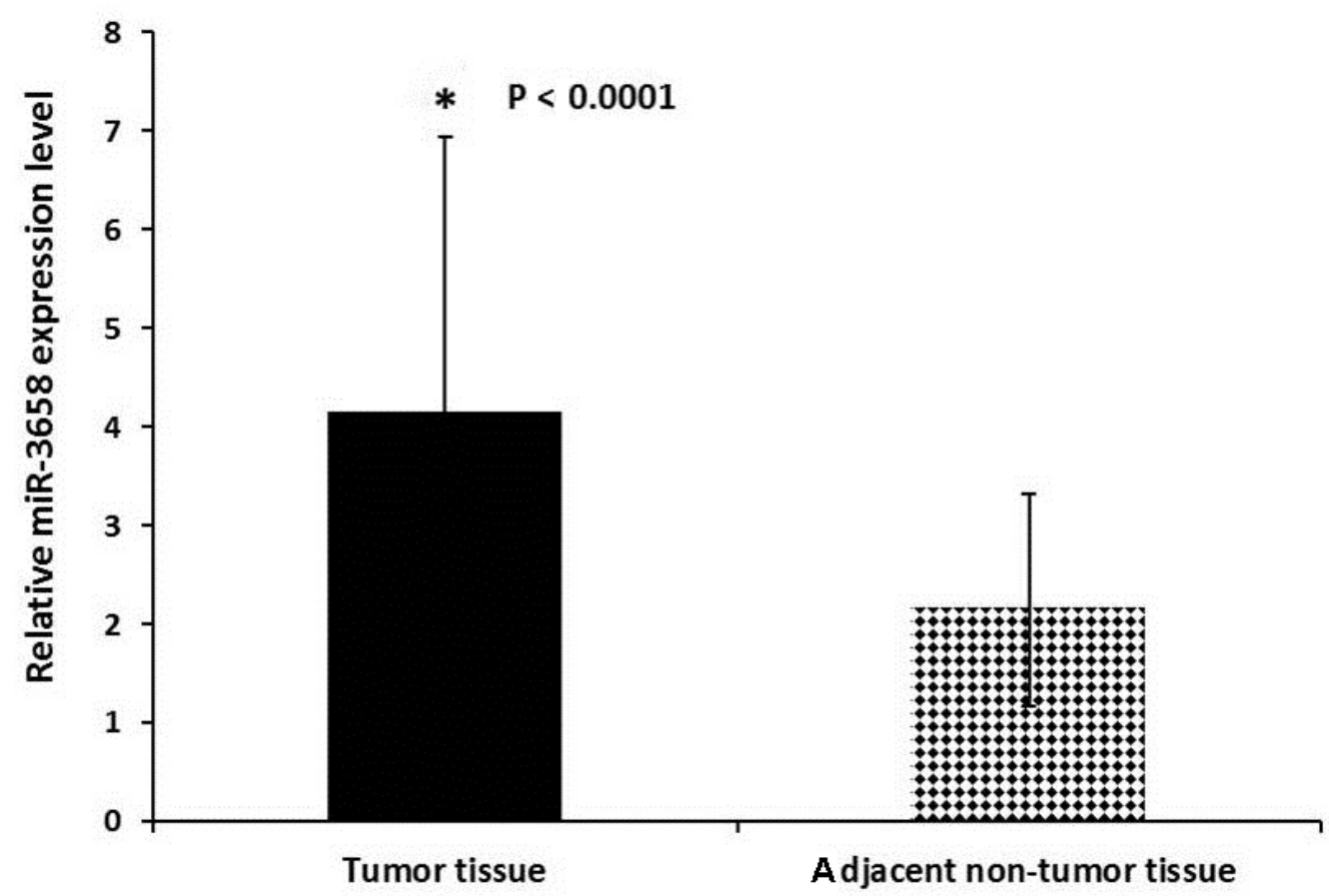

Figure 1. Comparison of miR-3658 expression in bladder cancer tissues and corresponding adjacent non-tumor tissues. Data are reported as means $\pm \mathrm{SD}$ and analyzed by the Student $t$-test. ${ }^{*} \mathrm{P}<0.0001$. 


\section{Correlation between miR-3658 expression and clinicopathological parameters}

The clinicopathological parameters of 96 patients with bladder cancer are summarized in Table 1. To further investigate the correlation between miR-3658 expression and the clinicopathological parameters, the relative expression levels of miR-3658 in the bladder cancer tissues and the corresponding control tissues were analyzed. The analysis showed that high expression of miR-3658 in bladder cancer was significantly associated with aggressive tumor phenotypes such as tumor recurrence $(t=7.172, \mathrm{P}<0.0001)$, lymph node invasion $(t=11.739, \mathrm{P}<0.0001)$, distant metastasis $(t=6.497, \mathrm{P}<0.0001)$, histological grade $(t=22.021, \mathrm{P}<0.0001)$, and TNM stage $(t=5.722, \mathrm{P}<0.0001)$. However, miR-3658 expression level in bladder cancer tissue was not associated with other clinicopathological variables such as age, gender, and tumor size and number (all $\mathrm{P}>0.05$ ). These results are summarized in Table 2. In brief, our data indicate that miR3658 was significantly up-regulated in the bladder cancer tissues, and its overexpression was closely associated with the clinicopathological features of tumor progression in the patients with bladder cancer.

\begin{tabular}{|c|c|}
\hline Clinical features & $\mathrm{N}(\%)$ \\
\hline Mean age (years, mean \pm SD) & $45.61 \pm 10.55$ \\
\hline \multicolumn{2}{|l|}{ Surgical procedure } \\
\hline Radical cystectomy & $96(100)$ \\
\hline \multicolumn{2}{|l|}{ Age (years) } \\
\hline$\geq 50$ & $36(37.5)$ \\
\hline$<50$ & $60(62.5)$ \\
\hline \multicolumn{2}{|l|}{ Gender } \\
\hline Male & $74(77.1)$ \\
\hline Female & $22(22.9)$ \\
\hline \multicolumn{2}{|l|}{ Tumor number } \\
\hline Single & $42(43.8)$ \\
\hline Multiple & $54(56.2)$ \\
\hline \multicolumn{2}{|l|}{ Tumor size } \\
\hline$\geq 3 \mathrm{~cm}$ & $53(55.2)$ \\
\hline$<3 \mathrm{~cm}$ & $43(44.8)$ \\
\hline \multicolumn{2}{|l|}{ Tumor histological grade } \\
\hline G1 & $30(31.2)$ \\
\hline G2 & $19(19.8)$ \\
\hline G3 & $47(49.0)$ \\
\hline \multicolumn{2}{|l|}{ TNM stage } \\
\hline $\mathrm{T} 1$ & $12(12.5)$ \\
\hline $\mathrm{T} 2$ & $49(51.0)$ \\
\hline $\mathrm{T} 3$ & $30(31.2)$ \\
\hline T4 & $5(5.3)$ \\
\hline \multicolumn{2}{|l|}{ Lymph node invasion } \\
\hline Positive & $64(66.7)$ \\
\hline Negative & $32(33.3)$ \\
\hline \multicolumn{2}{|l|}{ Distant metastasis } \\
\hline Positive & $86(89.6)$ \\
\hline Negative & $10(10.4)$ \\
\hline \multicolumn{2}{|l|}{ Tumor occurrence } \\
\hline Primary & $63(65.6)$ \\
\hline Recurrent & $33(34.4)$ \\
\hline
\end{tabular}


Table 2. Correlation between miR-3658 expression and different clinical pathological parameters of bladder cancer.

\begin{tabular}{|c|c|c|c|c|}
\hline Parameters & $\mathrm{N}$ & Relative miR-3658 level & $t$ value & $P$ value \\
\hline \multicolumn{5}{|l|}{ Age (years) } \\
\hline$\geq 50$ & 36 & $3.22 \pm 1.28$ & & \\
\hline$<50$ & 60 & $3.76 \pm 1.82$ & 1.701 & 0.092 \\
\hline \multicolumn{5}{|l|}{ Gender } \\
\hline Male & 74 & $2.61 \pm 1.21$ & & \\
\hline Female & 22 & $2.53 \pm 0.92$ & 0.286 & 0.775 \\
\hline \multicolumn{5}{|c|}{ Tumor number } \\
\hline Single & 42 & $3.27 \pm 1.92$ & & \\
\hline Multiple & 54 & $3.55 \pm 0.79$ & 0.888 & 0.378 \\
\hline \multicolumn{5}{|l|}{ Tumor size } \\
\hline$\geq 3 \mathrm{~cm}$ & 53 & $2.82 \pm 0.27$ & & \\
\hline$<3 \mathrm{~cm}$ & 43 & $2.62 \pm 1.56$ & 0.831 & 0.411 \\
\hline \multicolumn{5}{|c|}{ Tumor histological grade } \\
\hline $\mathrm{G} 1+\mathrm{G} 2$ & 49 & $1.19 \pm 0.32$ & & \\
\hline G3 & 47 & $4.10 \pm 0.85$ & 22.021 & $<0.0001$ \\
\hline \multicolumn{5}{|l|}{ TNM stage } \\
\hline $\mathrm{T} 1+\mathrm{T} 2$ & 61 & $2.14 \pm 2.03$ & & \\
\hline $\mathrm{T} 3+\mathrm{T} 4$ & 35 & $3.98 \pm 1.12$ & 5.722 & $<0.0001$ \\
\hline \multicolumn{5}{|c|}{ Lymph node invasion } \\
\hline Positive & 64 & $2.14 \pm 0.77$ & & \\
\hline Negative & 32 & $3.98 \pm 0.62$ & 11.739 & $<0.0001$ \\
\hline \multicolumn{5}{|c|}{ Distant metastasis } \\
\hline Positive & 86 & $2.03 \pm 0.84$ & & \\
\hline Negative & 10 & $3.83 \pm 0.72$ & 6.497 & $<0.0001$ \\
\hline \multicolumn{5}{|c|}{ Tumor occurrence } \\
\hline Primary & 63 & $1.48 \pm 0.56$ & & \\
\hline Recurrent & 33 & $3.93 \pm 1.92$ & 7.172 & $<0.0001$ \\
\hline
\end{tabular}

Data are reported as means \pm SD.

\section{DISCUSSION}

Bladder cancer is one of the most common urogenital tumors, and shows poor prognosis owing to cancer recurrence. Prevention of tumor recurrence and inhibition of disease progression are challenges that need to be overcome in the treatment of bladder cancer. Currently, clinicopathological parameters such as tumor stage, tumor grade, tumor number, and prior histories of tumor recurrence are used to evaluate prognosis of bladder cancer. However, their sensitivity and reliability have recently been questioned (Sanguedolce et al., 2015). Therefore, novel molecular markers are urgently needed to improve the prediction accuracy of disease progression and prognosis in bladder cancer, and can be used to explore more efficient, individualized therapeutic strategies.

miRNAs are single-strand, non-protein-coding RNA molecules. Studies have shown an association between miRNA deregulation in various tumors and clinicopathological characteristics, including clinical outcomes. It was further suggested that miRNAs can act as oncogenes or anti-oncogenes, and are involved in cellular proliferation, differentiation, apoptosis, tumor invasion, and metastasis (Hede, 2005; Yu et al., 2010; Catto et al., 2011; Fan et al., 2013; Han et al., 2013; Drayton et al., 2014; Feng et al., 2014; Wang et al., 2013, 2015). Recent studies have shown that several miRNAs are involved in the tumorigenesis and progression of bladder cancer. In addition, expressions of these miRNAs were found to be abnormal in bladder cancer tissues. For example, down-regulated (such as miR-145, miR143, miR-99a/100, miR-1, miR-24-1, miR-101, and miR-125b) and up-regulated (such as miR-183, miR-96, miR17-5p, miR-20a, miR-9, miR-19a, and miR-222) miRNAs were able to 
act as tumor suppressors and oncogenes, respectively. Alterations in miRNA levels have been reported to be associated with tumor stages and grades, as well as with tumor aggressiveness, poor prognosis, and increased risk of death (Yamada et al., 2011; Han et al., 2011, 2013; Yoshino et al., 2013; Drayton et al., 2014; Feng et al., 2014; Inoguchi et al., 2014; Wang et al., 2010, 2014; Zhang et al., 2013, 2014a,b). These studies suggest that miRNAs may be useful as prognostic biomarkers and therapeutic targets in bladder cancer. Therefore, it is an important first step to explore miRNAs expression and its association with clinicopathological characteristics of bladder cancer.

Human miR-3658 is located on chromosome 1, and its reference mature sequence is 5'-UUUAAGAAAACACCAUGGAGAU-3' (GenBank accession No. MIMAT0018078), according to the miRBase database. Meiri et al. (2010) first identified miR-3658 via high throughput sequencing in RNA extracted from 23 breast, bladder, colon, and lung solid-tumor specimens. Subsequently, Hao et al. (2015) found that miR-3658 is dysregulated in multiple myeloma (MM) serum samples, via miRCURY LNA microRNA arrays and qRT-PCR; they showed that the RQ value ( $\left.2^{-\Delta \Delta C t}\right)$ of miR-3658 was significantly increased in the MM group as compared with that in the healthy donor group $(1.74 v s 0.12, \mathrm{P}=0.025)$. These findings indicated that miR-3658 plays an important role in the development and progression of various tumors.

However, the role of miR-3658 in bladder cancer remains unknown. To explore miR-3658 expression and its clinical significance in bladder cancers, we measured miR-3658 expression in 96 pairs of bladder cancer tissues and their adjacent non-tumor tissues. We found that miR-3658 was significantly up-regulated in the bladder cancer tissues. In addition, we also found that higher miR-3658 expression was closely associated with aggressive clinicopathological characteristics of bladder cancer, such as high tumor grade, poor TNM stage, lymph node, and distant metastasis, as well as tumor recurrence. These data suggested that miR-3658 may act as an oncogenic miRNA, and may be used as potential prognostic biomarker for bladder cancers.

In this study, we indicated the potential connection between miR-3658 and aggressive clinicopathological characteristics of bladder cancer for the first time. However, the precise mechanisms of miR-3658 in gene regulation, such as its target genes and gene-gene interactions, remain unclear. Recently, Cipollini et al. (2014) computationally predicted that the alleles of rs 1819698, in strong linkage disequilibrium with rs1417608, disrupt the binding site for miR-3658 (DeltaS 0.571). Single nucleotide polymorphism of rs 1417608 located in the 3 '-untranslated regions of the hormone regulation gene 3-beta-hydroxysteroid dehydrogenase type $2(H S D 3 B 2)$ was associated with a nearly 2-fold increase in bladder cancer risk (Andrew et al., 2012). HSD3B2 encodes $\mathrm{NAD}^{+}$-dependent microsomal enzymes that stimulate biosynthesis and inactivation of many types of steroid hormones. Simard et al. (2005) reported that $H S D 3 B 2$ is predominantly expressed in the adrenal glands and gonads, and its deficiency could affect the synthesis of adrenal glands and gonads. Morbidity due to bladder cancer is approximately three times more prevalent in males than in females (Kaufman et al., 2009; Torre et al., 2015), but the reasons remain unknown. Miyamoto et al. (2012) reported that both androgens and androgen receptors are involved in the occurrence and development of bladder cancer. However, our data showed that miR-3658 expression in bladder cancer tissues was not associated with gender $(\mathrm{P}=0.775)$, suggesting that functions of miR-3658 may target downstream genes in the gene-regulatory network.

We utilized the web tool in the TargetScan7.0 database (http://www.targetscan.org/) to predict target genes of miR-3658. The analysis yielded a list of 6099 predicted targets for miR-

Genetics and Molecular Research 15 (4): gmr15049048 
3658. Besides the HSD3B gene family (HSD3B1, HSD3B2), ceramide synthases (CERS; CERS3, CERS4, CERS6) were also included in the list of predicted target genes. The CERS gene is also known as a longevity assurance gene (LASS). The CERS gene family consists of six members (CERS1-6), and encode key enzymes for sphingolipids biosynthesis and critical intermediates in the occurrence and development of malignant tumors (Reynolds et al., 2004). Of the six members, CERS2 (also known as LASS2) was identified to play an important role in inhibiting tumor cell proliferation and invasion of various cancers such as prostate, liver, and breast cancer (Su et al., 2008; Tang et al., 2010; Mei et al., 2015) . Our previous study showed that LASS2-negative bladder cancer is correlated with poor clinical prognosis (Wang et al., 2012), and down-regulation of LASS2 promotes proliferation and invasion of bladder cancer cells (Zhao et al., 2013). These results implied that HSD3B2 and LASS2 are involved in the onset and development of bladder cancer, and are potential target genes of miR-3658. However, further studies are needed to clarify the regulatory mechanisms of miR-3658 in gene regulation and its significance as a biomarker in bladder cancer.

In conclusion, we report that up-regulation of miR-3658 is closely associated with aggressive clinicopathological characteristics such as lymph node invasion, distant metastasis, tumor recurrence, poor histological grade, and high TNM stage in bladder cancer. This indicates that miR-3658 possesses potential prognostic values. However, further investigations should be performed to better understand the significance of this miRNA and its role in bladder cancer.

\section{Conflicts of interest}

The authors declare no conflict of interest.

\section{ACKNOWLEDGMENTS}

Research supported by the National Natural Science Foundation of China (\#81260374, \#81460384), the Yunnan Provincial Department of Education Fund (\#2014Z072), the Joint Project of Science and Technology, Department of Yunnan and Kunming Medical University (\#2014FA015, \#2014FZ031), the Project of Yunnan Provincial Health Department (\#2014NS081), and the Project of Yunnan Provincial Science and Technology (\#2015FB196).

\section{REFERENCES}

Andrew AS, Hu T, Gu J, Gui J, et al. (2012). HSD3B and gene-gene interactions in a pathway-based analysis of genetic susceptibility to bladder cancer. PLoS One 7: e51301. http://dx.doi.org/10.1371/journal.pone.0051301

Calin GA and Croce CM (2006). MicroRNA signatures in human cancers. Nat. Rev. Cancer 6: 857-866. http://dx.doi. org/10.1038/nrc1997

Calin GA, Sevignani C, Dumitru CD, Hyslop T, et al. (2004). Human microRNA genes are frequently located at fragile sites and genomic regions involved in cancers. Proc. Natl. Acad. Sci. USA 101: 2999-3004. http://dx.doi.org/10.1073/ pnas.0307323101

Cambier S, Sylvester RJ, Collette L, Gontero P, et al. (2016). EORTC nomograms and risk groups for predicting recurrence, progression, and disease-specific and overall survival in non-muscle-invasive stage Ta-T1 urothelial bladder cancer patients treated with 1-3 years of maintenance Bacillus Calmette-Guerin. Eur. Urol. 69: 60-69. http:// dx.doi.org/10.1016/j.eururo.2015.06.045

Catto JW, Alcaraz A, Bjartell AS, De Vere White R, et al. (2011). MicroRNA in prostate, bladder, and kidney cancer: a systematic review. Eur. Urol. 59: 671-681. http://dx.doi.org/10.1016/j.eururo.2011.01.044

Cipollini M, Landi S and Gemignani F (2014). MicroRNA binding site polymorphisms as biomarkers in cancer

Genetics and Molecular Research 15 (4): gmr15049048 
management and research. Pharm. Genomics Pers. Med. 7: 173-191.

Drayton RM, Peter S, Myers K, Miah S, et al. (2014). MicroRNA-99a and 100 mediated upregulation of FOXA1 in bladder cancer. Oncotarget 5: 6375-6386. http://dx.doi.org/10.18632/oncotarget.2221

Fan MQ, Huang CB, Gu Y, Xiao Y, et al. (2013). Decrease expression of microRNA-20a promotes cancer cell proliferation and predicts poor survival of hepatocellular carcinoma. J. Exp. Clin. Cancer Res. 32: 21. http://dx.doi. org/10.1186/1756-9966-32-21

Feng Y, Liu J, Kang Y, He Y, et al. (2014). miR-19a acts as an oncogenic microRNA and is up-regulated in bladder cancer. J. Exp. Clin. Cancer Res. 33: 67. http://dx.doi.org/10.1186/s13046-014-0067-8

Han Y, Chen J, Zhao X, Liang C, et al. (2011). MicroRNA expression signatures of bladder cancer revealed by deep sequencing. PLoS One 6: e18286. http://dx.doi.org/10.1371/journal.pone.0018286

Han Y, Liu Y, Zhang H, Wang T, et al. (2013). Hsa-miR-125b suppresses bladder cancer development by down-regulating oncogene SIRT7 and oncogenic long noncoding RNA MALAT1. FEBS Lett. 587: 3875-3882. http://dx.doi. org/10.1016/j.febslet.2013.10.023

Hao M, Zang M, Wendlandt E, Xu Y, et al. (2015). Low serum miR-19a expression as a novel poor prognostic indicator in multiple myeloma. Int. J. Cancer 136: 1835-1844. http://dx.doi.org/10.1002/ijc.29199

Hede K (2005). Studies define role of microRNA in cancer. J. Natl. Cancer Inst. 97: 1114-1115. http://dx.doi.org/10.1093/ jnci/dji260

Herr HW (1999). The value of a second transurethral resection in evaluating patients with bladder tumors. J. Urol. 162: 74-76. http://dx.doi.org/10.1097/00005392-199907000-00018

Hisataki T, Miyao N, Masumori N, Takahashi A, et al. (2000). Risk factors for the development of bladder cancer after upper tract urothelial cancer. Urology 55: 663-667. http://dx.doi.org/10.1016/S0090-4295(99)00563-4

Inoguchi S, Seki N, Chiyomaru T, Ishihara T, et al. (2014). Tumour-suppressive microRNA-24-1 inhibits cancer cell proliferation through targeting FOXM1 in bladder cancer. FEBS Lett. 588: 3170-3179. http://dx.doi.org/10.1016/j. febslet.2014.06.058

Kaufman DS, Shipley WU and Feldman AS (2009). Bladder cancer. Lancet 374: 239-249. http://dx.doi.org/10.1016/ $\underline{\mathrm{S} 0140-6736(09) 60491-8}$

Liu J, Wang H, Wang Y, Li Z, et al. (2016). Repression of the miR-93-enhanced sensitivity of bladder carcinoma to chemotherapy involves the regulation of LASS2. Onco Targets Ther. 9: 1813-1822.

Livak KJ and Schmittgen TD (2001). Analysis of relative gene expression data using real-time quantitative PCR and the 2(-Delta Delta C(T)) Method. Methods 25: 402-408. http://dx.doi.org/10.1006/meth.2001.1262

Mehta N, Rathore RS, Pillai BS, Sam MP, et al. (2015). Intrinsic tumour factors affecting recurrence in non muscle invasive bladder cancer: a hospital based study from India. Asian Pac. J. Cancer Prev. 16: 2675-2677. http://dx.doi. org/10.7314/APJCP.2015.16.7.2675

Mei F, You J, Liu B, Zhang M, et al. (2015). LASS2/TMSG1 inhibits growth and invasion of breast cancer cell in vitro through regulation of vacuolar ATPase activity. Tumour Biol. 36: 2831-2844. http://dx.doi.org/10.1007/s13277-014-2910-0

Meiri E, Levy A, Benjamin H, Ben-David M, et al. (2010). Discovery of microRNAs and other small RNAs in solid tumors. Nucleic Acids Res. 38: 6234-6246. http://dx.doi.org/10.1093/nar/gkq376

Meister G (2007). miRNAs get an early start on translational silencing. Cell 131: 25-28. http://dx.doi.org/10.1016/j. cell.2007.09.021

Miyamoto H, Zheng Y and Izumi K (2012). Nuclear hormone receptor signals as new therapeutic targets for urothelial carcinoma. Curr. Cancer Drug Targets 12: 14-22. http://dx.doi.org/10.2174/156800912798888965

Philippe L, Alsaleh G, Suffert G, Meyer A, et al. (2012). TLR2 expression is regulated by microRNA miR-19 in rheumatoid fibroblast-like synoviocytes. J. Immunol. 188: 454-461. http://dx.doi.org/10.4049/jimmunol.1102348

Reynolds CP, Maurer BJ and Kolesnick RN (2004). Ceramide synthesis and metabolism as a target for cancer therapy. Cancer Lett. 206: 169-180. http://dx.doi.org/10.1016/j.canlet.2003.08.034

Sanguedolce F, Cormio A, Bufo P, Carrieri G, et al. (2015). Molecular markers in bladder cancer: Novel research frontiers. Crit. Rev. Clin. Lab. Sci. 52: 242-255. http://dx.doi.org/10.3109/10408363.2015.1033610

Simard J, Ricketts ML, Gingras S, Soucy P, et al. (2005). Molecular biology of the 3beta-hydroxysteroid dehydrogenase/ delta5-delta4 isomerase gene family. Endocr. Rev. 26: 525-582. http://dx.doi.org/10.1210/er.2002-0050

Su J, You JF, Wang JL, Cui XL, et al. (2008). Overexpression of human tumor metastasis-related gene TMSG-1 suppresses cell proliferation and invasion of a highly metastatic prostate cancer cell line PC-3M-1E8 in vitro. Zhonghua Zhong Liu Za Zhi 30: 404-407.

Sylvester RJ, van der Meijden AP, Oosterlinck W, Witjes JA, et al. (2006). Predicting recurrence and progression in individual patients with stage Ta T1 bladder cancer using EORTC risk tables: a combined analysis of 2596 patients from seven EORTC trials. Eur. Urol. 49: 466-477, discussion 475-477. http://dx.doi.org/10.1016/j.eururo.2005.12.031

Genetics and Molecular Research 15 (4): gmr15049048 
Tang N, Jin J, Deng Y, Ke RH, et al. (2010). LASS2 interacts with V-ATPase and inhibits cell growth of hepatocellular carcinoma. Sheng Li Xue Bao 62: 196-202.

Torre LA, Bray F, Siegel RL, Ferlay J, et al. (2015). Global cancer statistics, 2012. CA Cancer J. Clin. 65: 87-108. http:// dx.doi.org/10.3322/caac. 21262

Wang G, Kwan BC, Lai FM, Chow KM, et al. (2010). Expression of microRNAs in the urinary sediment of patients with IgA nephropathy. Dis. Markers 28: 79-86. http://dx.doi.org/10.1155/2010/396328

Wang H, Wang J, Zuo Y, Ding M, et al. (2012). Expression and prognostic significance of a new tumor metastasis suppressor gene LASS2 in human bladder carcinoma. Med. Oncol. 29: 1921-1927. http://dx.doi.org/10.1007/s12032$\underline{011-0026-6}$

Wang H, Zhang W, Zuo Y, Ding M, et al. (2015). miR-9 promotes cell proliferation and inhibits apoptosis by targeting LASS2 in bladder cancer. Tumour Biol. 36: 9631-9640. http://dx.doi.org/10.1007/s13277-015-3713-7

Wang T, Yuan J, Feng N, Li Y, et al. (2014). Hsa-miR-1 downregulates long non-coding RNA urothelial cancer associated 1 in bladder cancer. Tumour Biol. 35: 10075-10084. http://dx.doi.org/10.1007/s13277-014-2321-2

Wang Z, Wang J, Yang Y, Hao B, et al. (2013). Loss of has-miR-337-3p expression is associated with lymph node metastasis of human gastric cancer. J. Exp. Clin. Cancer Res. 32: 76. http://dx.doi.org/10.1186/1756-9966-32-76

Yamada Y, Enokida H, Kojima S, Kawakami K, et al. (2011). MiR-96 and miR-183 detection in urine serve as potential tumor markers of urothelial carcinoma: correlation with stage and grade, and comparison with urinary cytology. Cancer Sci. 102: 522-529. http://dx.doi.org/10.1111/j.1349-7006.2010.01816.x

Yoshino H, Seki N, Itesako T, Chiyomaru T, et al. (2013). Aberrant expression of microRNAs in bladder cancer. Nat. Rev. Urol. 10: 396-404. http://dx.doi.org/10.1038/nrurol.2013.113

Yu S, Lu Z, Liu C, Meng Y, et al. (2010). miRNA-96 suppresses KRAS and functions as a tumor suppressor gene in pancreatic cancer. Cancer Res. 70: 6015-6025. http://dx.doi.org/10.1158/0008-5472.CAN-09-4531

Zhang DQ, Zhou CK, Jiang XW, Chen J, et al. (2014a). Increased expression of miR-222 is associated with poor prognosis in bladder cancer. World J. Surg. Oncol. 12: 241. http://dx.doi.org/10.1186/1477-7819-12-241

Zhang H, Qi F, Cao Y, Chen M, et al. (2014b). Down-regulated microRNA-101 in bladder transitional cell carcinoma is associated with poor prognosis. Med. Sci. Monit. 20: 812-817. http://dx.doi.org/10.12659/MSM.890300

Zhang QH, Sun HM, Zheng RZ, Li YC, et al. (2013). Meta-analysis of microRNA-183 family expression in human cancer studies comparing cancer tissues with noncancerous tissues. Gene 527: 26-32. http://dx.doi.org/10.1016/j. gene.2013.06.006

Zhao Q, Wang H, Yang M, Yang D, et al. (2013). Expression of a tumor-associated gene, LASS2, in the human bladder carcinoma cell lines BIU-87, T24, EJ and EJ-M3. Exp. Ther. Med. 5: 942-946.

Genetics and Molecular Research 15 (4): gmr15049048 